University of South Carolina

Scholar Commons

$12-1-2007$

\title{
Species Invasion Shifts the Importance of Predator Dependence
}

\author{
Blaine D. Griffen \\ University of South Carolina - Columbia, bgriffen@biol.sc.edu \\ David G. Delaney \\ McGill University
}

Follow this and additional works at: https://scholarcommons.sc.edu/biol_facpub

Part of the Biology Commons, and the Ecology and Evolutionary Biology Commons

\section{Publication Info \\ Published in Ecology, ed. P. T. Raimondi, Volume 88, Issue 12, 2007, pages 3012-3021. \\ (C) Ecology 2007, Ecological Society of America}

This Article is brought to you by the Biological Sciences, Department of at Scholar Commons. It has been accepted for inclusion in Faculty Publications by an authorized administrator of Scholar Commons. For more information, please contact digres@mailbox.sc.edu. 


\title{
SPECIES INVASION SHIFTS THE IMPORTANCE OF PREDATOR DEPENDENCE
}

\author{
Blaine D. Griffen ${ }^{1,3}$ and David G. Delaney ${ }^{2}$ \\ ${ }^{1}$ Odum School of Ecology, University of Georgia, Athens, Georgia 30602-2202 USA \\ ${ }^{2}$ Department of Biology and School of Environment, McGill University, Montreal, Quebec H3A 1 B1 Canada
}

\begin{abstract}
The strength of interference between foraging individuals can influence per capita consumption rates, with important consequences for predator and prey populations and system stability. Here we demonstrate how the replacement of a previously established invader, the predatory crab Carcinus maenas, by the recently invading predatory crab Hemigrapsus sanguineus shifts predation from a species that experiences strong predator interference (strong predator dependence) to one that experiences weak predator interference (weak predator dependence). We demonstrate using field experiments that differences in the strength of predator dependence persist for these species both when they forage on a single focal prey species only (the mussel Mytilus edulis) and when they forage more broadly across the entire prey community. This shift in predator dependence with species replacement may be altering the biomass across trophic levels, consistent with theoretical predictions, as we show that $H$. sanguineus populations are much larger than $C$. maenas populations throughout their invaded ranges. Our study highlights that predator dependence may differ among predator species and demonstrates that different predatory impacts of two conspicuous invasive predators may be explained at least in part by different strengths of predator dependence.
\end{abstract}

Key words: Carcinus maenas; functional response; Hemigrapsus sanguineus; Mytilus edulis; predator interference; ratio dependence.

\section{INTRODUCTION}

Consumer-resource interactions are an integral part of natural communities and the rate of resource consumption can have important implications for population and community dynamics. Early predation theory assumed that predation rate was a function of prey density only, leading to prey-dependent functional responses (Holling 1959). The influence of predator interference on predation rates was subsequently noted (Beddington 1975), and it has been suggested that prey and predator densities may be equally important so that predation rates are a function of the ratio between the two (Arditi and Ginzburg 1989). Under ratio-dependent foraging, predation rates generally increase with prey density up to some maximum level and decrease with predator density.

Whether predator foraging is prey dependent or ratio dependent has ramifications for community and population dynamics. Predator-prey models based on preydependent foraging predict that increased productivity of basal resources transfers through the food chain, alternately influencing the biomass of each trophic level depending on food chain length (Rosenzweig 1977, Oksanen et al. 1981, Arditi and Ginzburg 1989). In addition, these abundance changes are predicted to decrease the dynamic stability of the food web (i.e., the

Manuscript received 1 February 2007; revised 17 April 2007; accepted 23 April 2007. Corresponding Editor: P. T. Raimondi.

3 E-mail: bgriffen@uga.edu paradox of enrichment [Rosenzweig 1971]). In contrast, models based on ratio-dependent foraging predict that increasing productivity at the resource level will in turn increase abundance at each level of the food chain, including basal resources, prey, and predators, and will not affect food web stability (Arditi and Ginzburg 1989, Arditi and Akcakaya 1990, Arditi et al. 1991).

While considerable attention has been devoted to theoretical aspects of these predation strategies, and the relative merits of prey dependence vs. ratio dependence weighed, disagreement remains over which null model provides the appropriate starting point for ecological theory (reviewed by Abrams and Ginzburg 2000). However, these are two extremes of a continuum, and most species likely have varying levels of predator dependence and thus fall somewhere in between, depending on the level of conspecific interference among predators (Arditi and Akcakaya 1990, Abrams and Ginzburg 2000). Yet even if predation is not purely prey dependent or ratio dependent, the strength of predator interference has tremendous consequences for ecological systems, as interference stabilizes predator-prey dynamics and can lead to lower predator population sizes (Arditi et al. 2004). While theoretical aspects of this issue have been heavily debated, there have been few empirical tests of the competing theories, and the paucity of empirical evidence impedes determining where most organisms lie along the continuum (Abrams and Ginzburg 2000). 
Because the strength of predator dependence likely varies with idiosyncrasies of predator species, changes in predator species composition or dominance within a system could potentially shift the importance of predator dependence. As a case in point, the introduction of nonnative predators has altered the species composition and dominance of predators in intertidal habitats along the northeast coast of North America. Until recently the dominant crab was the European green crab Carcinus maenas, an aggressive predator that was first noted in New York and New Jersey nearly two centuries ago (Say 1817). However, in 1988 a second species of exotic predatory crab, the Asian shore crab Hemigrapsus sanguineus, was documented in New Jersey (Williams and McDermott 1990; see Plate 1). H. sanguineus has spread rapidly along the Atlantic coast (McDermott 1998), largely eliminating C. maenas from rocky intertidal regions with its advancing invasion (Lohrer and Whitlatch 2002a). While H. sanguineus frequently consumes more plant material than $C$. maenas, both crabs are generalist predators that eat many of the same prey species (Ropes 1968, Elner 1981, Tyrrell and Harris 1999, Bourdeau and O'Connor 2003, Brousseau and Baglivo 2005). However, if the shift in dominant shore crabs from $C$. maenas to $H$. sanguineus has altered the importance of predator dependence for the dominant predator, then community implications may extend beyond slight differences in diet preferences.

Interference among predatory crabs is a widespread phenomenon (Mansour and Lipcius 1991, Clark et al. 1999, Taylor and Eggleston 2000, Sietz et al. 2001, Mistri 2003), and C. maenas and H. sanguineus are no exception (Jensen et al. 2002, Mistri 2003, Griffen 2006, Smallegange et al. 2006). Interference both between and within these species generally takes the form of aggressive interactions, resulting in reduced feeding rates (Griffen 2006, Griffen and Byers 2006a, Smallegange et al. 2006), injury (Davis et al. 2005), and predator mortality (Griffen and Byers 2006b). However, experimental evidence suggests that aggressive interactions among conspecifics are much stronger for $C$. maenas than for $H$. sanguineus (B. D. Griffen and T. Williamson, unpublished manuscript), and in fact conspecific aggression in the form of cannibalism can control C. maenas population size (Moksnes 2004). More aggression among conspecifics may thus translate into a greater influence of predator density on C. maenas predation than $H$. sanguineus predation. If this is the case, then based on theoretical predictions (Rosenzweig 1971, Arditi and Ginzburg 1989, Arditi et al. 2004), shifting from a $C$. maenas-dominated system to an $H$. sanguineus-dominated system may alter the distribution of biomass across trophic levels in the invaded system, potentially resulting in greater predator abundance and lower system stability.

We investigated the strength of predator dependence for each of these species using field experiments in which we measure predation both on a single, favored prey species, and predation when the entire range of prey commonly used by these predators is available to them. We also conducted population sampling throughout the invaded regions of these two species along the New York and New England coasts in order to determine whether the shift in dominant species is altering population abundance (density and/or biomass) at the predator trophic level.

\section{Methods}

We conducted two separate experiments in June and July 2006 to determine the influence of predator density on foraging by $C$. maenas and $H$. sanguineus. Both were conducted in field enclosures $(0.5 \times 0.6 \times 0.3 \mathrm{~m})$ constructed of lobster wire, lined with $0.25 \mathrm{~cm}$ plastic mesh, and deployed $0.5 \mathrm{~m}$ above mean low water within an intertidal boulder field at south Odiorne Point, New Hampshire. This site is a moderately exposed site dominated by small boulders overlying a substrate of shell and sand. Crab density varies considerably throughout the site, but was relatively low in the area surrounding the enclosures (C. maenas, $2.8 \pm 2.8$ crabs $/ \mathrm{m}^{2} ; H$. sanguineus, $1.5 \pm 1.8 \mathrm{crabs} / \mathrm{m}^{2}$ [values are means $\pm \mathrm{SD}]$ ). Boulders from the surrounding area were placed inside experimental enclosures to provide the same structurally complex habitat as is found naturally at our field site.

\section{Functional response experiment}

The first experiment examined whether functional responses of $C$. maenas and $H$. sanguineus were best described by prey-dependent or ratio-dependent models. We measured predation by both of these predators independently while foraging at densities of one, two, or four predators per cage (C. maenas, 40-60 mm carapace width [CW]; H. sanguineus, 25-33 mm CW) on mussel prey (Mytilus edulis) at densities of 5, 10, 15, 20, 25, 30, 45,60 , or 90 mussels per cage. Crab densities used here $\left(\sim 3-13 \mathrm{crabs} / \mathrm{m}^{2}\right)$, are similar to the range of densities observed during low tide sampling at our field site $(0-12$ crabs $/ \mathrm{m}^{2}$ of the sizes used here for both species; B. Griffen, unpublished data). The range of mussel densities is also consistent with that observed at our field site (Tyrrell 2002). Predator and prey treatments listed above resulted in 27 different predator-prey combinations for each predator species. Four trials were conducted at each of these combinations. Our purpose in this experiment was to assess predation at specified levels of prey abundance. We therefore removed all other potential food items from experimental enclosures (i.e., boulders inside cages were denuded) so that the only prey available were the mussels we provided. Mussels were haphazardly scatted into cages $24 \mathrm{~h}$ before the addition of predators to allow time for byssal thread attachment. At the conclusion of each trial, the contents of each cage were removed and mussel survival was assessed. 


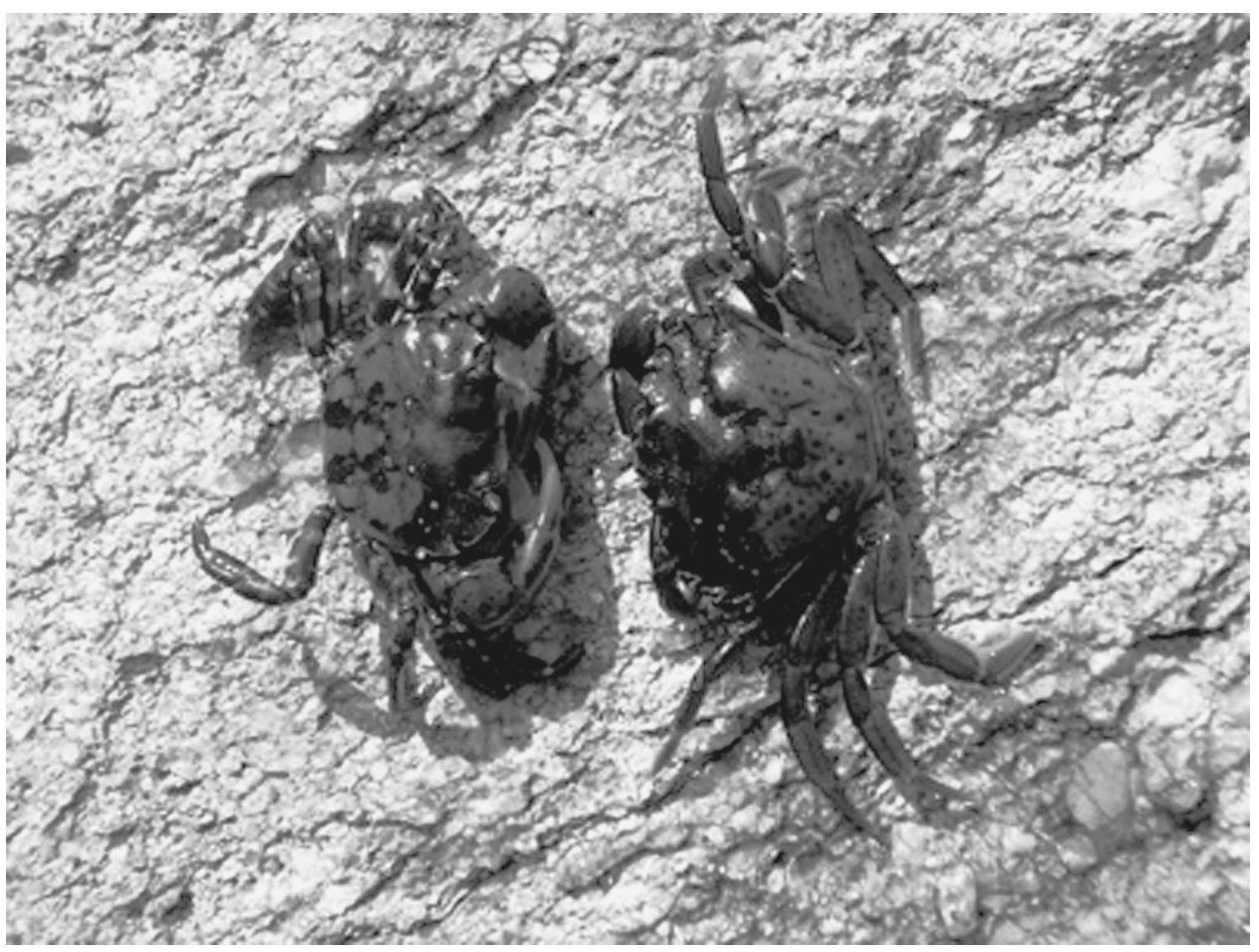

Plate 1. (Left) The Asian shore crab Hemigrapsus sanguineus and (right) the European green crab Carcinus maenas, two invasive crabs currently inhabiting the U.S. East Coast. Photo credit: Julia Buck.

Previous experiments in this system demonstrated that the per capita rate of mussel consumption by adult $C$. maenas is approximately twice that of $H$. sanguineus (Griffen 2006) and that these two species prefer different sizes of mussel prey (Elner and Hughes 1978, DeGraaf and Tyrrell 2004). These differences lead to very different levels of prey depletion when these species forage for the same length of time on the same sized mussels (Lohrer and Whitlatch 2002b, Griffen 2006). To avoid confounding our results by having different amounts of prey depletion (Abrams 1994), we approximately equalized total prey depletion by conducting experiments with $C$. maenas for $24 \mathrm{~h}$ and experiments with $H$. sanguineus for $48 \mathrm{~h}$, and by presenting each species with its preferred mussel size (C. maenas, 14-17 $\mathrm{mm}$ shell length; $H$. sanguineus, $7-10 \mathrm{~mm}$ ). We verified that the results reported here were not artifacts of these experimental differences by conducting a simplified supplementary experiment where both crab species were fed the same size mussels over the same experimental duration (Appendix A).

Data analysis for this experiment was a three step process and followed the procedures outlined by Juliano (2001). Analyses were conducted on per capita predation. We first determined the shape of the functional response curves for each of the three predator densities of each crab species (six curves total) using separate polynomial logistic regressions. Conclusions from these analyses were verified by visual inspection of plots of proportion of prey eaten vs. initial prey density.

We next estimated the parameters of the functional response equation (handling time and search efficiency) using nonlinear least squares regression for each of the six curves. This was done to understand how predator density influenced the mechanisms of predation for $C$. maenas and $H$. sanguineus. As logistic regression indicated type III functional responses for both predators at all three densities, we fit the data to a type III functional response model that accounts for prey depletion, as occurred in our experiments, and that incorporated the different experimental durations for the two crabs (Eq. 10.5 from Juliano 2001). Estimates of handling time and search efficiency that were provided by fitting the data to this model were then compared between different predator density treatments using individual $t$ tests (Glantz and Slinker 1990, Juliano 2001, Fussmann et al. 2005).

Finally, our overarching goal was to determine whether $C$. maenas' and $H$. sanguineus' predation was explained better by the prey-dependent or ratiodependent model. We developed the ratio-dependent model by replacing initial prey density $\left(N_{0}\right)$ in Juliano's Eq. 10.5 (Juliano 2001), with the ratio of prey to predators $N_{0} / P^{m}$ (Hassel and Varley 1969), where $P$ is the number of predators in an enclosure, and $m$ is an interference coefficient. When $m=0$, the model reduces to the prey-dependent form. Ratio dependence is 
modeled when $m=1$. Intermediate values of $m$ represent varying degrees of predator dependence. We fit the data for each predator species (across all predator densities simultaneously) to models ranging from prey dependence to ratio dependence at intervals of $m=0.1$. We determined which of these models fit the data best by choosing the model with the smallest residual sum of squares (i.e., the one with the least amount of variability that was not explained by the model) (Fussmann et al. 2005). These statistical analyses are described in more detail in Appendix B.

\section{Influence of omnivory}

C. maenas and $H$. sanguineus are both omnivorous (Ropes 1968, Elner 1981, Tyrrell and Harris 1999, Lohrer et al. 2000). We conducted a second experiment to determine the effect of predator density when these predators had the choice of several different prey taxa that are available to them under natural conditions. Boulders that had a full compliment of naturally occurring flora and fauna, including barnacles, snails, limpets, urchins, mussels, and macroalgae were placed in field enclosures.

We allowed crabs to forage in enclosures for $24 \mathrm{~h}$ at one of nine predator densities: $1,2,3,4,5,6,7,8$, or 10 crabs per cage. The experimental design was uneven (more replicates of lower predator densities were used) to approximately equalize the numbers of crabs used in the analysis from treatments at each of the predator densities (resulting in 7-12 crabs from each predator density). Since crabs forage predominantly during nighttime high tides (Lindberg 1980, Willason 1981, Batie 1983, Depledge 1984, Saigusa and Kawagoye 1997), experiments were terminated at dawn on ebbing tides to ensure that crabs had foraged as recently as possible. Upon termination of the experiment, crabs were immediately placed in $95 \%$ ethanol for later dissection. We determined the mass of material present in the gut of each crab by removing the cardiac stomach and passing its contents through a $6-\mu \mathrm{m}$ Ahlstrom filter. Filters were then dried at $70^{\circ} \mathrm{C}$ for $24 \mathrm{~h}$, and then each was weighed. We corrected for differences in crab size by using the residual mass of the stomach contents for each crab after accounting for crab carapace width (i.e., the variance in stomach mass not explained by crab size) as the response variable in a regression analysis against the number of crabs in the cage for each species.

\section{Population sampling}

We sampled populations of $C$. maenas and $H$. sanguineus to determine whether the replacement of $C$. maenas by $H$. sanguineus has altered the overall abundance of predatory crabs throughout the invaded region. We used two metrics of abundance, density and biomass. Because $C$. maenas attains much larger maximum sizes than $H$. sanguineus, similar densities of these species may result in very different biomasses.
Further, both metrics may influence and/or reflect the degree of interference. We therefore measured both.

We sampled crabs at 30 sites over a $700-\mathrm{km}$ transect from Rye, New York, USA $\left(40^{\circ} 34^{\prime} 49^{\prime \prime}\right.$ N, $73^{\circ} 23^{\prime} 62^{\prime \prime}$ W) to West Quoddy Head, Maine, USA $\left(44^{\circ} 29^{\prime} 40^{\prime \prime} \mathrm{N}\right.$, $\left.66^{\circ} 34^{\prime} 16^{\prime \prime} \mathrm{W}\right)$. Sampling was conducted from late June to late August 2006. Sampling of sites at different latitudes was interspersed throughout this time period to avoid confounding seasonal changes with latitudinal changes. At each site we determined the number of crabs of each species, their carapace width, and gender within 16 randomly interspersed $1-\mathrm{m}^{2}$ quadrats throughout the mid and lower intertidal zones. We determined biomass of each crab species at each site using empirically derived relationships between carapace width and biomass for male and female C. maenas combined and for male and female $H$. sanguineus separately (because $H$. sanguineus is sexually dimorphic) $\left(R^{2} \geq 0.99\right.$ for each relationship; B. Griffen, unpublished data).

In comparing the abundance of $C$. maenas and $H$. sanguineus across our sampling range, it was necessary to control for latitudinal changes in environmental factors that exogenously influence crab abundance. While the use of ANCOVA with latitude as a covariate would have been ideal, the inverse gradient of the two species across our sampling range violated the assumption of homogenous slopes (Engqvist 2005). We therefore conducted an alternative analysis in which we converted latitude into a categorical variable, thus allowing us to compare $C$. maenas and $H$. sanguineus abundance in different parts of our sampling range (D'Alonzo 2004). To do this' we divided our sampling range into three regions: sites from Cape Cod south where $H$. sanguineus has been present for more than a decade and has likely achieved maximum population abundance (Kraemer et al., in press), sites within the Gulf of Maine where H. sanguineus has been present for less than a decade and is still increasing in abundance, and sites within the Gulf of Maine where $H$. sanguineus has not yet arrived. We then conducted separate twoway ANOVAs on $\log$ density and log biomass with species and sampling region as fixed factors, followed by planned linear contrasts to compare the abundance of $C$. maenas and $H$. sanguineus in each of the three regions.

\section{RESUlts}

\section{Functional response experiment}

Maximum mussel consumption by $C$. maenas and $H$. sanguineus was similar over the duration of our experiment (Fig. 1A, B), indicating that differences in the importance of predator density are not due to differences in the amount of prey depletion between predator species. Both $C$. maenas and $H$. sanguineus had type III functional responses at all three predator densities (significant positive linear term and negative quadratic term in the polynomial logistic regression). Statistical analyses were confirmed by plots of propor- 

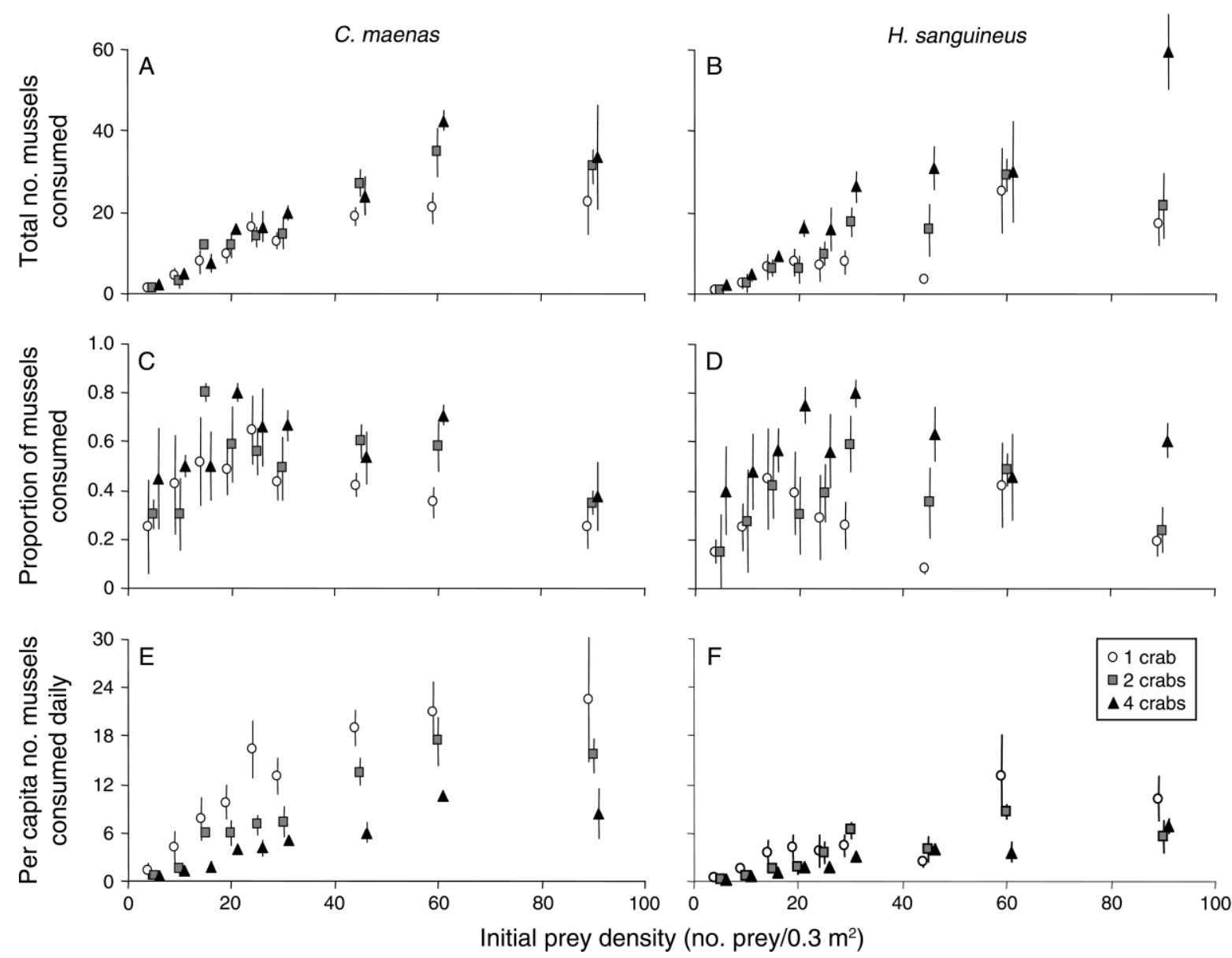

Fig. 1. (A, C, E) Functional response of Carcinus maenas and (B, D, F) Hemigrapsus sanguineus at different densities while foraging on mussel prey. Values are means \pm SE ( $n=4$ replicates). Panels A and B show the total number of prey consumed over the course of the experiment at different initial prey densities. Panels $\mathrm{C}$ and D show the proportion of prey consumed at different initial prey densities. Panels $\mathrm{E}$ and $\mathrm{F}$ show the per capita daily prey consumption at different initial prey densities.

tion of prey consumed vs. initial prey density (Fig. $1 \mathrm{C}, \mathrm{D})$.

C. maenas' per capita daily mussel consumption decreased in a more consistent manner with increasing predator density than that of $H$. sanguineus (Fig. 1E, F). The type III functional response model provided a highly significant fit to the data (nonlinear regression, $F_{2,34}>34, P<0.0001$ for all six predator combinations), and yielded estimates of handling times and searching efficiencies for each. Model parameters indicated that changes in foraging by $C$. maenas with predator density resulted both from increases in handling time and decreases in searching efficiency at higher predator densities (Fig. 2). Whereas for $H$. sanguineus, prey handling time increased at higher predator densities, but there was no effect of predator density on searching efficiency (Fig. 2).

These changes in handling time and searching efficiency with increasing predator density resulted in predator-dependent foraging for both $C$. maenas and $H$. sanguineus, though to very different degrees. Foraging by $C$. maenas was strongly predator dependent, and was described best by the functional response model with an exponent $(m)$ of 0.9 (i.e., this model explained the most variation in the data and thus had the lowest residual sum of squares; Table 1). (The residual sum of squares was actually lowest using the purely ratio-dependent model for $C$. maenas; however, confidence intervals for parameter estimates with this model included zero.) In contrast, $H$. sanguineus foraging was influenced very little by predator density, and despite high variability in $H$. sanguineus predation rates (Fig. 1F), its foraging was described best by the functional response model with an exponent of 0.1 (Table 1). Thus, $C$. maenas and $H$. sanguineus forage on opposite ends of the ratiodependent-prey-dependent continuum.

\section{Influence of omnivory}

The relative importance of predator density for $C$. maenas and $H$. sanguineus predation was unaffected by increasing the number of prey choices available. When all naturally available prey types were available to them, 

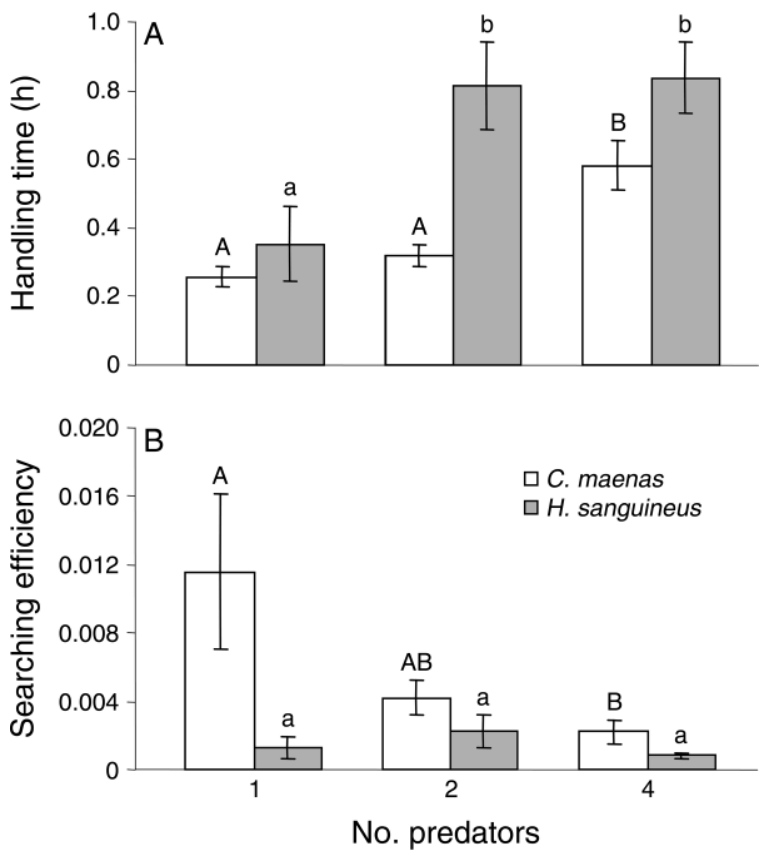

FIG. 2. Estimates (mean $\pm \mathrm{SE}$ ) of handling time and searching efficiency for Carcinus maenas and Hemigrapsus sanguineus at different predator densities as determined by nonlinear least-squares regression. Letters over bars indicate statistically significant differences based on individual $t$ tests $(\alpha=0.05)$. Uppercase letters indicate comparisons among $C$. maenas only, and lowercase letters indicate comparisons among $H$. sanguineus only (i.e., comparisons were not made between species).

C. maenas consumed on average $45 \%$ mussels, the rest of the diet being comprised mainly of barnacles and red algae, while $H$. sanguineus consumed mainly red algae and mussels made up on average only $30 \%$ of their diet. Though variability was high, particularly at low

TABLE 1. Residual sum of squares from fit of different models to functional response data.

\begin{tabular}{ccc}
\hline \hline$m$ & Carcinus maenas & Hemigrapsus sanguineus \\
\hline 0.0 & 26091.7 & 27393.8 \\
0.1 & 20416.5 & 24292.7 \\
0.2 & 16088.1 & 36053.7 \\
0.3 & 12124.0 & 33404.0 \\
0.4 & 10785.9 & 33398.9 \\
0.5 & 6885.0 & 30001.7 \\
0.6 & 6050.9 & 28851.1 \\
0.7 & 6554.1 & 28362.2 \\
0.8 & 4257.1 & 27785.1 \\
0.9 & 4126.6 & 27975.1 \\
1.0 & $961.5 \dagger$ & 30049.6 \\
\hline
\end{tabular}

Notes: The left-hand column represents the variable $m$ in the functional response equation; $m$ is 0 in the prey-dependent model and 1 in the ratio-dependent model. Intermediate levels represent varying degrees of predator dependence.

$\dagger$ While this model yielded the lowest residual sum of squares, indicating that $C$. maenas predation may be strictly ratio dependent, parameter estimates (for handling times and searching efficiency) with this model were not significant. We therefore concluded that the model with the next lowest residual sum of squares (with $m=0.9$ ) provided the best fit.

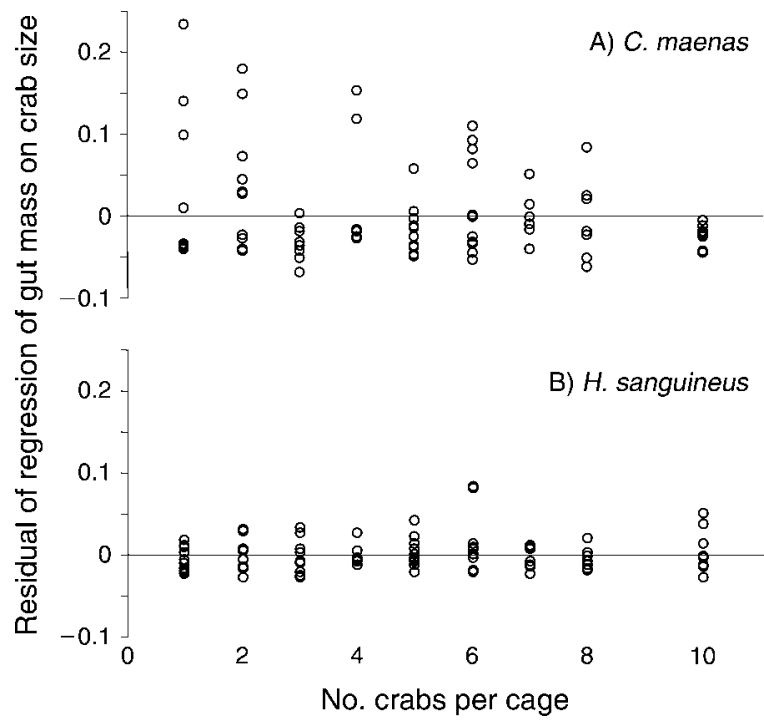

FIG. 3. Residual mass of stomach contents after crab size is accounted for at different predator densities. Data points represent individual crabs.

predator densities, the amount of food consumed by individual $C$. maenas (gut content mass) decreased with increasing predator density (regression, $P=0.05, R^{2}=$ 0.04; Fig. 3A). Predator density had no impact on the amount of food consumed by individual $H$. sanguineus (regression, $P=0.23, R^{2}=0.02$, Fig. 3B).

\section{Population sampling}

The mean density of $H$. sanguineus was more variable across sites $\left(0-79.5 \mathrm{crabs} / \mathrm{m}^{2}\right)$ than that of $C$. maenas $\left(0.1-7.9 \mathrm{crabs} / \mathrm{m}^{2}\right)$, and the relative density of the two species differed by sampling region. Specifically, $H$. sanguineus was more dense than $C$. maenas in the region south of Cape Cod $\left(F_{1,54}=50.65, P<<0.001\right.$; region 1 in Fig. 4). At sites within the Gulf of Maine where $H$. sanguineus has already invaded, but has been present for a relatively short time period, the density of the two species is similar $\left(F_{1,54}=0.07, P=0.79\right.$; region 2 in Fig. 4). Pemaquid Point, Maine represents the northernmost extent of $H$. sanguineus' invaded range, and only $C$. maenas was found at sites north of this $\left(F_{1,54}=12.72, P\right.$ $<0.001$; region 3 in Fig. 4). Averaging across all three of these regions, $H$. sanguineus population densities were nearly six times greater than those of C. maenas (Fig. 4).

Despite the large body size of $C$. maenas, patterns in biomass were identical to those of density reported above. Specifically, the mean biomass of $H$. sanguineus was more variable $\left(0-224.9 \mathrm{~g} / \mathrm{m}^{2}\right)$ than that of $C$. maenas $\left(0.004-35.2 \mathrm{~g} / \mathrm{m}^{2}\right)$. H. sanguineus had higher biomass in the region south of Cape $\operatorname{Cod}\left(F_{1,54}=30.51, P \ll 0.001\right.$; region 1 in Fig. 4). The two species were similar in biomass in southern Gulf of Maine sites $\left(F_{1,54}=0.23, P\right.$ $=0.63$; region 2 in Fig. 4). C. maenas biomass was higher by default in northern sites where $H$. sanguineus has not yet invaded $\left(F_{1,54}=15.73, P<0.001\right.$; region 3 in Fig. 4$)$. 


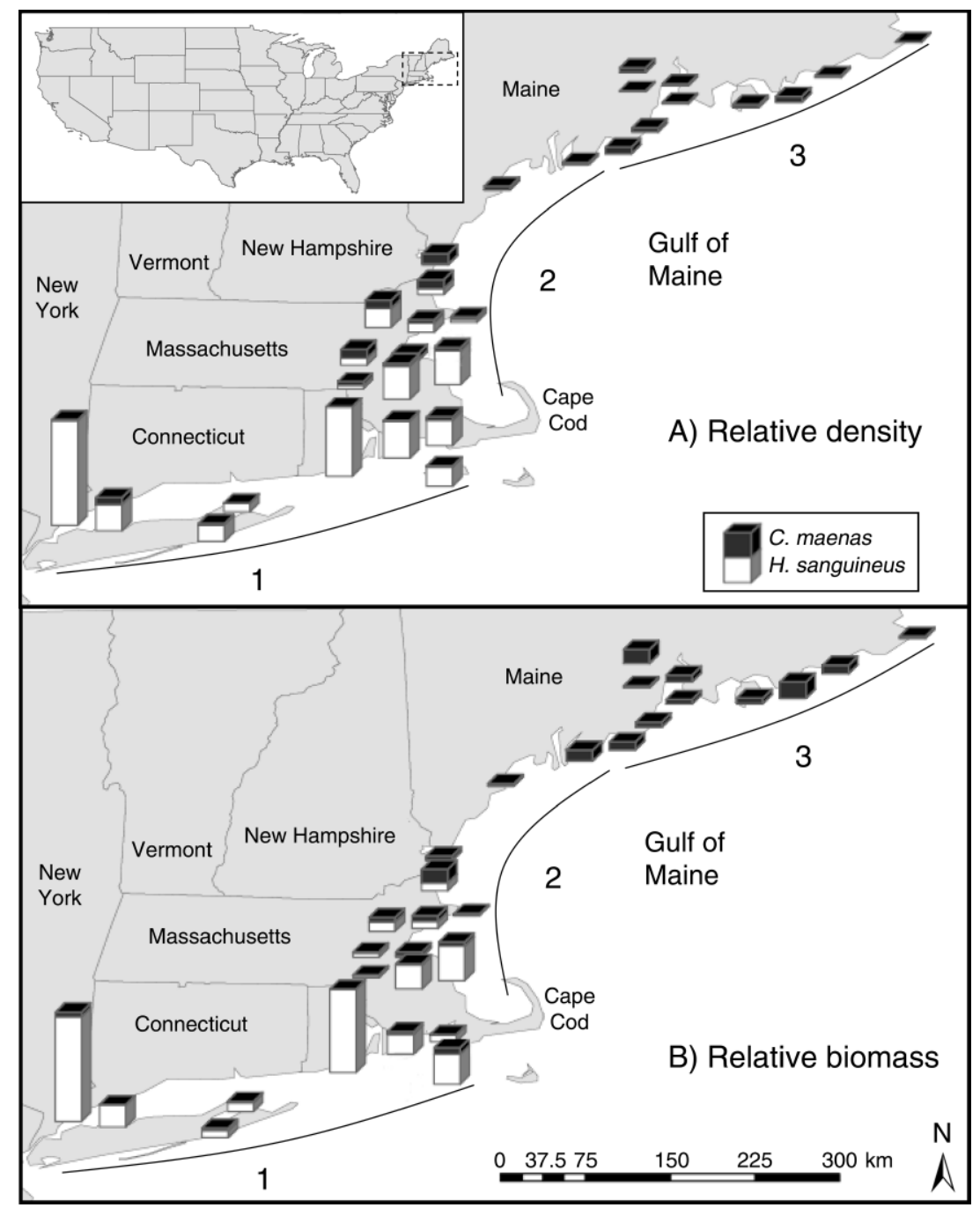

FIG. 4. (A) Density and (B) biomass of Carcinus maenas and Hemigrapsus sanguineus at 30 sites throughout their invaded ranges. Heights of bars indicate relative mean values ( $n=16$ values per site). Lines drawn along the coast and corresponding numbers demonstrate three different regions for statistical analysis.

Qualitative results of these analyses were unchanged when the two sites with extremely high $H$. sanguineus abundance were excluded.

\section{DISCUSSION}

Few studies have examined the strength of predator dependence in field settings (Reeve 1997, Vucetich et al. 2002, Schenk et al. 2005). We have shown that predator dependence was stronger for $C$. maenas than for $H$. sanguineus when each foraged in field enclosures in the same habitat and on the same prey resources. This is consistent with previous findings that $C$. maenas is more aggressive towards conspecifics than is H. sanguineus (B. D. Griffen and T. Williamson, unpublished manuscript), and that prey handling times and searching efficiency of C. maenas are both negatively influenced at high predator densities (Smallegange et al. 2006). This study provides additional evidence that foraging may frequently fall short of either pure ratio dependence or pure prey dependence (Abrams and Ginzburg 2000, Hansson et al. 2001, Schenk et al. 2005); but rather, as was the case for both $C$. maenas and H. sanguineus (Table 1), predation may often fall somewhere along the continuum between these extremes. The difference in predator dependence by two species of intertidal crabs also cautions that the strength of predator dependence is species specific and that generalizations that apply across broad taxonomic groups (such as across all intertidal crabs) may not be possible.

Lower predator densities for C. maenas than for $H$. sanguineus are consistent with theoretical prediction that interference can reduce predator abundance (Arditi et al. 2004). Other factors besides conspecific interference may also influence maximum predator density, including the 
availability of prey, food conversion efficiency, and food-independent predator mortality (Arditi and Ginzburg 1989, Arditi et al. 2004). However, predator interference and aggression may also influence these factors. For example, interference that reduces consumption rates (Fig. 1E, F) can lead to slower individual growth rates for both of these species (Griffen et al., in press), and may thus indirectly increase predator mortality by increasing the time susceptible to sizedependent predation threats (deRivera et al. 2005). In addition, extreme conspecific aggression (i.e., cannibalism) is an important source of mortality for C. maenas and can directly limit population size for this species due to its density-dependent nature (Moksnes 2004). Predator interference and aggression may therefore act in multiple ways to differentially influence the densities of these two species, and may thus at least partially explain both the small size of current $C$. maenas populations at sites outside the invaded range of $H$. sanguineus (zone 3 in Fig. 4), and the small historical C. maenas densities that were replaced by larger $H$. sanguineus densities at the same sites (Lohrer and Whitlatch 2002a, b, and references therein).

Not only are these species influenced differently by intraspecific interference, but they are also influenced differently by interspecific interference. C. maenas eats less and alters its diet to consume less favorable food in the presence of $H$. sanguineus, while $H$. sanguineus predation is unaffected by interactions with $C$. maenas (Griffen et al., in press). This implies that in regions of overlap when these two species forage together, predation by $C$. maenas is likely still heavily predator dependent, but the important predator density is the combined density of $C$. maenas plus $H$. sanguineus; while predation by $H$. sanguineus is only weakly influenced by interactions with conspecifics or heterospecifics, and is thus still likely only weakly predator dependent when foraging side by side with $C$. maenas.

The differential effect of predator interference for these two species may potentially contribute to the observed shift from a $C$. maenas to an $H$. sanguineus dominated system. When only C. maenas is present, interference decreases as predator density declines (Fig. 1E). In contrast, when interference occurs with a heterospecific that is not influenced by the interaction (i.e., H. sanguineus) this inherent negative feedback is eliminated. Thus, from an interference perspective, $H$. sanguineus densities may increase because of low interference from C. maenas or from conspecifics, while C. maenas populations may be depressed by strong interference from both $H$. sanguineus and conspecifics, and this interference is not lessened as C. maenas densities decline because of concurrently increasing $H$. sanguineus densities.

$H$. sanguineus has only been present in the Gulf of Maine since the late 1990s (McDermott 1998). A previous report indicated that $H$. sanguineus densities on the New Hampshire coast were ten times lower than
C. maenas densities for the first few years following its arrival (Tyrrell et al. 2006). Our study indicates $H$. sanguineus densities in this region are climbing, and are now similar to densities of $C$. maenas. Given the latitudinal range of native $H$. sanguineus populations in the western Pacific (McDermott 1998 and references therein), the continued spread of $H$. sanguineus is likely. However, as this new invader increases in abundance within the Gulf of Maine, it is uncertain whether it will reach high densities similar to those seen south of Cape Cod or whether it will displace C. maenas from rocky intertidal areas as it has in southern regions (Lohrer and Whitlatch 2002a). Current C. maenas densities for southern Gulf of Maine sites reported here are similar to historical densities before the arrival of $H$. sanguineus (Menge 1983), suggesting that displacement of $C$. maenas has not yet occurred.

While not strictly ratio dependent or prey dependent, the large differences in the importance of predator interference for $C$. maenas and $H$. sanguineus may have important consequences for the invaded community where $H$. sanguineus has displaced C. maenas to become the dominant predatory crab (Lohrer and Whitlatch 2002a). Much attention has been given to potential changes in community structure that may result from this species shift (Tyrrell and Harris 1999, Lohrer et al. 2000, Lohrer and Whitlatch 2002b, Tyrrell et al. 2006). These studies have focused largely on diets of the two predators and how diet choice may affect predation pressure on various prey taxa. Our study highlights an additional mechanism by which a change in the dominance of these two predators in the invaded region may impact the native community. Even when predation is not strictly prey dependent, decreasing predator interference has a destabilizing influence in predatorprey systems (Arditi et al. 2004) that can lead to oscillatory predator-prey cycles of increasing amplitude (Hassell and May 1973). Thus, replacement of $C$. maenas (high predator dependence) with $H$. sanguineus (low predator dependence) may decrease system stability. This is consistent with drastic reductions in the abundance of mussel prey that have been reported in areas where $H$. sanguineus has achieved very high densities (Lohrer and Whitlatch 2002b), and with large effects of this species across the broader prey community (Tyrrell et al. 2006). Whether high densities of $H$. sanguineus will be able to persist in the face of depressed prey abundances, or whether a lack of food will eventually drive down $H$. sanguineus densities remains to be seen. However, given the open nature of both $H$. sanguineus and prey populations in intertidal habitats, increasing predator-prey oscillations that lead to local species extinction are unlikely.

We have demonstrated that while foraging by two predatory crabs is neither strictly prey dependent nor ratio dependent, their foraging falls at different ends of this continuum. Anthropogenic disturbance via the introduction of $H$. sanguineus, together with its subse- 
quent displacement of $C$. maenas, has shifted the importance of predator dependence in our study system. Weaker predator dependence for $H$. sanguineus than for $C$. maenas may at least partially explain why this new invader has achieved higher population densities and can have greater impacts on the native community (Lohrer and Whitlatch 2002b, Tyrrell et al. 2006).

\section{ACKNOWLEDGMENTS}

Portions of this work were funded by the National Sea Grant College Program, National Oceanic and Atmospheric Administration (NA05OAR4171088), and U.S. Department of Commerce. We thank I. Altman, A. Blakeslee, J. Byers, M. F. Delaney, G. F. Fussmann, W. J. Lee, and L. Page for comments on the manuscript. We also thank A. Malek and S. Trottier for assistance in field work.

\section{Literature Cited}

Abrams, P. A. 1994. The fallacies of "ratio-dependent" predation. Ecology 75:1842-1850.

Abrams, P. A., and L. R. Ginzburg. 2000. The nature of predation: prey dependent, ratio dependent or neither? Trends in Ecology and Evolution 15:337-341.

Arditi, R., and H. R. Akcakaya. 1990. Underestimation of mutual interference of predators. Oecologia 83.

Arditi, R., J. Callois, Y. Tyutyunov, and C. Jost. 2004. Does mutual interference always stabilize predator-prey dynamics? A comparison of models. C. R. Biologies 327:1037-1057.

Arditi, R., and L. R. Ginzburg. 1989. Coupling in predatorprey dynamics: ratio dependence. Journal of Theoretical Biology 139:311-326.

Arditi, R., L. R. Ginzburg, and H. R. Akcakaya. 1991. Variation in plankton densities among lakes: a case for ratiodependent predation models. American Naturalist 138:12871296.

Batie, R. E. 1983. Rhythmic locomotor activity in the intertidal shore-crab Hemigrapsus oregonensis (Brachyura, Grapsidae) from the Oregon Coast. Northwest Science 57:49-56.

Beddington, J. R. 1975. Mutual interference between parasites or predators and its effect on searching efficiency. Journal of Animal Ecology 44:331-340.

Bourdeau, P. E., and J. N. O'Connor. 2003. Predation by the nonindigenous Asian shore crab Hemigrapsus sanguineus on macroalgae and molluscs. Northeastern Naturalist 10:319334.

Brousseau, D. J., and J. A. Baglivo. 2005. Laboratory investigations of food selection by the Asian shore crab, Hemigrapsus sanguineus: algal versus animal preference. Journal of Crustacean Biology 25:130-134.

Clark, M. E., T. G. Wolcott, D. L. Wolcott, and A. H. Hines. 1999. Intraspecific interference among foraging blue crabs Callinectes sapidus: interactive effects of predator density and prey patch distribution. Marine Ecology-Progress Series 178: 69-78.

D'Alonzo, K. T. 2004. The Johnson-Neyman procedure as an alternative to ANCOVA. Western Journal of Nursing Research 26:804-812.

Davis, L. D., N. A. Dobroski, J. T. Carlton, J. Prevas, S. Parks, D. Hong, and E. Southwarth. 2005. Autotomy in the Asian shore crab (Hemigrapsus sanguineus) in a non-native area of its range. Journal of Crustacean Biology 25:655-660.

DeGraaf, J. D., and M. C. Tyrrell. 2004. Comparison of the feeding rates of two introduced crab species, Carcinus maenas and Hemigrapsus sanguineus, on blue mussel, Mytilus edulis. Northeastern Naturalist 11:163-167.

Depledge, M. H. 1984. Cardiac activity in the intertidal crab Hemigrapsus sanguineus (de Haan). Asian Marine Biology 1: 115-123.
deRivera, C. E., G. M. Ruiz, A. H. Hines, and P. Jivoff. 2005. Biotic resistance to invasion: native predator limits abundance and distribution of an introduced crab. Ecology 86: 3364-3376.

Elner, R. W. 1981. Diet of green crab Carcinus maenas (L.) from Port Herbert, southwestern Nova Scotia. Journal of Shellfish Research 1:89-94.

Elner, R. W., and R. N. Hughes. 1978. Energy maximization in the diet of the shore crab, Carcinus maenas. Journal of Animal Ecology 47:103-116.

Engqvist, L. 2005. The mistreatment of covariate interaction terms in linear model analysis of behavioural and evolutionary ecology studies. Animal Behaviour 70:967-971.

Fussmann, G. F., G. Weithoff, and T. Yoshida. 2005. A direct, experimental test of resource vs. consumer dependence. Ecology 86:2924-2930.

Glantz, S. A., and B. K. Slinker. 1990. Primer of applied regression and analysis of variance. McGraw-Hill, New York, New York, USA.

Griffen, B. D. 2006. Detecting emergent effects of multiple predator species. Oecologia 148:702-709.

Griffen, B. D., and J. E. Byers. 2006a. Intraguild predation reduces redundancy of predator species in multiple predator assemblage. Journal of Animal Ecology 75:959-966.

Griffen, B. D., and J. E. Byers. 2006b. Partitioning mechanisms of predator interference in different habitats. Oecologia 146: 608-614.

Griffen, B. D., T. Guy, and J. Buck. 2007. Inhibition between invasives: a newly introduced predator moderates the impacts of a previously established invasive predator. Journal of Animal Ecology, in press.

Hansson, S., B. T. De Stasio, E. Gorokhova, and M. A. Mohammadian. 2001. Ratio-dependent functional responses: tests with the zooplanktivore Mysis mixta. Marine EcologyProgress Series 216:181-189.

Hassell, M. P., and R. M. May. 1973. Stability in insect hostparasite models. Journal of Animal Ecology 42:693-726.

Hassel, M. P., and G. C. Varley. 1969. New inductive population model for insect parasites and its bearing on biological control. Nature 223:1133-1137.

Holling, C. S. 1959. The components of predation as revealed by a study of small mammal predation of the European pine sawfly. Canadian Journal of Entomology 91:293-320.

Jensen, G. C., P. S. McDonald, and D. A. Armstrong. 2002. East meets west: competitive interactions between green crab Carcinus maenas, and native and introduced shore crab Hemigrapsus spp. Marine Ecology-Progress Series 225:251262.

Juliano, S. A. 2001. Nonlinear curve fitting: predation and functional response curves. Pages 178-196 in S. M. Scheiner and J. Gurevitch, editors. Design and analysis of ecological experiments. Oxford University Press, New York, New York, USA.

Kraemer, G. P., M. Sellberg, A. Gordon, and J. Maine. 2007. Eight-year record of Hemigrapsus sanguineus invasion: population dynamics of the invader, resident crabs, and Littorina littorea in western Long Island Sound estuary. Northeastern Naturalist 42:207-224.

Lindberg, W. J. 1980. Behavior of the Oregon mud crab, Hemigrapsus oregonensis (Dana) (Brachyura, Grapsidae). Crustaceana 39:262-280.

Lohrer, A. M., and R. B. Whitlatch. 2002a. Interactions among aliens: apparent replacement of one exotic species by another. Ecology 83:710-732.

Lohrer, A. M., and R. B. Whitlatch. 2002b. Relative impacts of two exotic brachyuran species on blue mussel populations in Long Island Sound. Marine Ecology Progress Series 227: 135-144.

Lohrer, A. M., R. B. Whitlatch, K. Wada, and F. Yasuo. 2000. Home and away: comparison of resource utilization by a 
marine species in native and invaded habitats. Biological Invasions 2:41-57.

Mansour, R. A., and R. N. Lipcius. 1991. Density-dependent foraging and mutual interference in blue crabs preying upon infaunal clams. Marine Ecology-Progress Series 72:239-246.

McDermott, J. J. 1998. The western Pacific brachyuran (Hemigrapsus sanguineus: Grapsidae), in its new habitat along the Atlantic coast of the United States: geographic distribution and ecology. Journal of Marine Science 55:289298.

Menge, B. A. 1983. Components of predation intensity in the low zone of the New England rocky intertidal region. Oecologia 58:141-155.

Mistri, M. 2003. Foraging behaviour and mutual interference in the Mediterranean shore crab, Carcinus aestuarii, preying upon the immigrant mussel Musulista senhousia. Estuarine, Coastal, and Shelf Science 56:155-159.

Moksnes, P. O. 2004. Self-regulating mechanisms in cannibalistic populations of juvenile shore crabs Carcinus maenas. Ecology 85:1343-1354.

Oksanen, L., S. D. Fretwell, J. Arruda, and P. Niemelä. 1981. Exploitation ecosystems in gradients of the primary production. American Naturalist 118:240-261.

Reeve, J. D. 1997. Predation and bark beetle dynamics. Oecologia 112:48-54.

Ropes, J. W. 1968. The feeding habits of the green crab, Carcinus maenas (L.). Fisheries Bulletin 67:183-203.

Rosenzweig, M. L. 1971. Paradox of enrichment: destabilization of exploitation ecosystems in ecological time. Science 171:385-387.

Rosenzweig, M. L. 1977. Aspects of biological exploitation. Quarterly Review of Biology 52:371-380.

Saigusa, M., and O. Kawagoye. 1997. Circatidal rhythm of an intertidal crab, Hemigrapsus sanguineus: synchrony with unequal tide height and involvement of a light response mechanism. Marine Biology 129:87-96.

Say, T. 1817. An account of the Crustacea of the United States. Journal of the Academy of Natural Sciences Philadelphia 1: $53-63$.
Schenk, D., L. Bersier, and S. Bacher. 2005. An experimental test of the nature of predation: neither prey- nor ratiodependent. Journal of Animal Ecology 74:86-91.

Sietz, R. D., R. N. Lipcius, A. H. Hines, and D. B. Eggleston. 2001. Density-dependent predation, habitat variation, and the persistence of marine bivalve prey. Ecology 82:24352451.

Smallegange, I. M., J. van der Meer, and R. H. J. M. Kurvers. 2006. Disentangling interference competition from exploitative competition in a crab-bivalve system using a novel experimental approach. Oikos 113:157-167.

Taylor, D. L., and D. B. Eggleston. 2000. Effects of hypoxia on an estuarine predator-prey interaction: foraging behavior and mutual interference in the blue crab Callinectes sapidus and the infaunal clam prey Mya arenaria. Marine EcologyProgress Series 196:221-237.

Tyrrell, M. C. 2002. Impacts of the introduced crabs, Carcinus maenas and Hemigrapsus sanguineus, in northern New England. Dissertation. University of New Hampshire, Durham, New Hampshire, USA.

Tyrrell, M. C., P. A. Guarino, and L. G. Harris. 2006. Predatory impacts of two introduced crab species: inferences from mesocosms. Northeastern Naturalist 13:375-390.

Tyrrell, M. C., and L. G. Harris. 1999. Potential impact of the introduced Asian shore crab Hemigrapsus sanguineus, in northern New England: diet, feeding preferences, and overlap with the green crab, Carcinus maenas. Pages 208-220 in J. Pederson, editor. Proceedings of the National Conference on Marine Bioinvasions. Massachusetts Institute of Technology, Cambridge, Massachusetts, USA.

Vucetich, J. A., R. O. Peterson, and C. L. Schaefer. 2002. The effect of prey and predator densities on wolf predation. Ecology 83:3003-3013.

Willason, W. 1981. Factors influencing the distribution and coexistence of Pachygrapsus crassipes and Hemigrapsus oregonensis (Decapoda: Grapsidae) in a California Salt Marsh. Marine Biology 64:125-133.

Williams, A. B., and J. J. McDermott. 1990. An eastern United States record for the Western Indo-Pacific crab, Hemigrapsus sanguineus (Crustacea: Decapoda: Grapsidae). Proceedings of the Biological Society of Washington 103:108-109.

\section{APPENDIX A}

Experiment to examine potential artifacts in the main ratio-dependent experiment (Ecological Archives E088-187-A1).

\section{APPENDIX B}

Statistics used for functional response analysis (Ecological Archives E088-187-A2). 